\title{
Precipitation is the dominant driver for bird species richness, phylogenetic and functional structure in university campuses in northern China
}

\author{
Chenxia Liang ${ }^{1}$, Jun Liu ${ }^{1}$, Bin Pan ${ }^{2}$, Na Wang ${ }^{1}$, Jie Yang ${ }^{1,3^{*}}$, Guisheng Yang ${ }^{2}$ and Gang Feng ${ }^{1 *}$ (D)
}

\begin{abstract}
Background: Although urbanization is threatening biodiversity worldwide, the increasing green urban spaces could harbor relatively high biodiversity. Therefore, how to maintain the biodiversity in urban ecosystem is crucial for sustainable urban planning and management, especially in arid and semiarid regions with relatively fragile environment and low biodiversity. Here, for the first time we linked species richness, phylogenetic and functional structure of bird assemblages in university campuses in northern China with plant species richness, glacial-interglacial climate change, contemporary climate, and anthropogenic factors to compare their relative roles in shaping urban bird diversity.
\end{abstract}

Methods: Bird surveys were conducted in 20 university campuses across Inner Mongolia, China. Ordinary least squares models and simultaneous autoregressive models were used to assess the relationships between bird species richness, phylogenetic and functional structure with environmental factors. Structural equation models were used to capture the direct and indirect effects of these factors on the three components of bird diversity.

Results: Single-variable simultaneous autoregressive models showed that mean annual precipitation was consistently a significant driver for bird species richness, phylogenetic and functional structure. Meanwhile, mean annual temperature and plant species richness were also significant predictors for bird species richness.

Conclusions: This study suggests that campuses with warmer and wetter climate as well as more woody plant species could harbor more bird species. In addition, wetter campuses tended to sustain over-dispersed phylogenetic and functional structure. Our findings emphasize the dominant effect of precipitation on bird diversity distribution in this arid and semiarid region, even in the urban ecosystem.

Keywords: Climate, Human factors, Functional structure, Phylogenetic structure, Urban bird diversity, Woody plant diversity

*Correspondence: jyang@imu.edu.cn; qaufenggang@163.com ${ }^{1}$ Ministry of Education Key Laboratory of Ecology and Resource Use of the Mongolian Plateau \& Inner Mongolia Key Laboratory of Grassland Ecology, School of Ecology and Environment, Inner Mongolia University, Hohhot 010021, China

Full list of author information is available at the end of the article

\section{Background}

Urban land is one of the most fast growing land-use types, and the worldwide acceleration of urbanization will profoundly threat the global biodiversity (McDonald 2008; Aronson et al. 2014; Sol et al. 2014). Urbanized habitats always harbor some bird species with certain traits, e.g., generalists, omnivorous, cavities and canopy nesting species, while exclude others species, e.g., specialists,

(c) The Author(s) 2020. This article is licensed under a Creative Commons Attribution 4.0 International License, which permits use, sharing, adaptation, distribution and reproduction in any medium or format, as long as you give appropriate credit to the original author(s) and the source, provide a link to the Creative Commons licence, and indicate if changes were made. The images or other third party material in this article are included in the article's Creative Commons licence, unless indicated otherwise in a credit line to the material. If material is not included in the article's Creative Commons licence and your intended use is not permitted by statutory regulation or exceeds the permitted use, you will need to obtain permission directly from the copyright holder. To view a copy of this licence, visit http://creativeco mmons.org/licenses/by/4.0/. The Creative Commons Public Domain Dedication waiver (http://creativecommons.org/publicdomain/ zero/1.0/) applies to the data made available in this article, unless otherwise stated in a credit line to the data. 
ground nesting species (Conole and Kirkpatrick 2011; Leveau 2013). Although there is evidence that intermediate levels of urbanization may retain higher bird diversity than surrounding natural habitats and intensive urban areas, urban sprawl usually has negative effect on overall bird diversity (Lepczyk et al. 2008; McKinney 2008; Concepción et al. 2016). Meanwhile, urban green spaces may be considered as important "hotspots" of biodiversity, which could harbor high bird diversity (Cornelis and Hermy 2004; Ferenc et al. 2014; Zhang et al. 2018; Liu et al. 2019). Thus a better understanding of the drivers for variation of urban bird diversity is necessary for sustainable urban planning and biodiversity conservation.

Many anthropogenic drivers are crucial for urban bird diversity, e.g., area and age of green spaces, population density, number of buildings, and land-cover (Evans et al. 2009; Aronson et al. 2014; Huang et al. 2015; Gagné et al. 2016). For example, several studies demonstrate that size of green urban space is the best predictor of bird species richness (Thompson et al. 1993; Carbo-Ramirez and Zuria 2011; Huang et al. 2015). A global study suggests that bird species density (number of species per $\mathrm{km}^{2}$ ) is negatively associated with the proportion of urban landcover in cities (Aronson et al. 2014). In addition, it is also widely reported that number of woody vegetation and complex vegetation structure is important for the maintenance of urban bird diversity (Evans et al. 2009; Barth et al. 2015).

However, most studies on drivers of bird diversity in urban ecosystems focus on species richness (Lepczyk et al. 2008; Loss et al. 2009; de Toledo et al. 2012; Huang et al. 2015). But urban developments may also influence other dimensions of biodiversity, e.g., phylogenetic and functional diversity, which could better reflect the evolutionary characteristics and ecological differences of bird communities, respectively (Webb et al. 2002; Petchey and Gaston 2010). Recently, there are some studies about the taxonomic, phylogenetic and functional diversity of bird communities in urban areas (Morelli et al. 2017; Palacio et al. 2018; Liu et al. 2019). Nevertheless, few of these studies have considered the effect of woody plant species richness. In addition, although there are some studies about urban bird diversity in China, large-scale bird community data across cities in northern China, especially the arid and semiarid region, is still lacking.

Inner Mongolia spans about $3000 \mathrm{~km}$ from northeast to southwest, with marked precipitation and temperature gradients, and diverse vegetation (Wu et al. 2015). Here, for the first time we systematically investigated bird communities in university campuses and assessed drivers of different components of bird community diversity across cities of Inner Mongolia, an arid and semiarid region of northern China. Specifically, we hypothesized that contemporary climate would directly and indirectly affect bird diversity through their effects on physiological tolerance and primary productivity, especially for the precipitation in this dry region; glacial-interglacial climate change may mainly affect the phylogenetic structure of bird communities because phylogenetic information is linked with long-term evolutionary history; more plant species would maintain high bird diversity by providing diverse habitat for most species and more food for herbivores; bird diversity may be negatively linked with anthropogenic activities.

\section{Methods \\ Study area}

Inner Mongolia is located at the north and northeast of China, covering 120 million ha. It has great temperature and precipitation gradients, e.g., mean annual temperature and mean annual precipitation range from - 2 to $6{ }^{\circ} \mathrm{C}$ and about 40 to $450 \mathrm{~mm}$, respectively (Wu et al. 2015). The strong climate differentiation results in zonal distribution of diverse vegetation types (temperate coniferous and deciduous forests, meadow steppe, typical steppe, desert steppe, steppe desert, and desert) in this arid and semiarid region (Wu et al. 2015).

\section{Bird and woody plant surveys}

Bird and plant investigation was conducted in twenty university campuses across eight cities in Inner Mongolia between October 2017 and September 2018 (Additional file 2: Figure S1). Birds survey was investigated through both transect line and point count (two to six points according to the campus area) in each campus, and covered all the main habitats (e.g., teaching buildings, lawns, woodlands and ponds) in order to search thoroughly. Each campus was investigated four times by experienced observers during four seasons, one time for each season, and about $2.5 \mathrm{~h}$ in a visit. All survey was conducted during $3 \mathrm{~h}$ after sunrise and $3 \mathrm{~h}$ before sunset on clear weather. Sixty-eight bird species were recorded in total (Additional file 1: Table S1). Species accumulation curve was used to assess the adequacy of bird investigation (sample was adequate, Additional file 2: Figure S2). Migrants were excluded from our analyses because of its possible confounding effect on diversity patterns (Lepczyk et al. 2008). Therefore, only resident birds were used for diversity related analyses and campus with less than three species was excluded. Threatened status of the birds was checked according to a recent publication (Jiang et al. 2016). Woody plant (e.g., trees and shrubs) in all habitats was recorded by experienced observers. 


\section{Bird phylogeny and trait data}

A distribution of 5000 phylogenies was downloaded from the global phylogeny of birds (Jetz et al. 2012), including all 462 bird species in Inner Mongolia. Five thousand pseudo-posterior distributions were sampled, and the Maximum Clade Credibility tree was constructed using mean node heights by the software TreeAnnonator v1.8.2 of the BEAST package (Drummond and Rambaut 2007). The resulting consensus phylogeny was used for subsequent phylogenetic analyses.

Three traits (body size, trophic level, and habitat specificity) were selected to construct the functional dendrogram including all 462 bird species in Inner Mongolia for subsequent functional analyses. Traits data was compiled from the third and fourth volumes of Fauna of Inner Mongolia (Xu 2007, 2015). Trophic level was assigned as omnivores, granivores, frugivore, nectarivores, insectivores, piscivores and carnivores, and habitat specificity was coded according to the number of Chinese habitats that a bird inhabited (Wang et al. 2018). Distances of the three traits among all species were generated using Gower's distance. The functional dendrogram was then constructed by hierarchical clustering using 'complete' method.

\section{Climate and anthropogenic variables}

Contemporary climate data, including mean annual temperature (MAT) and mean annual precipitation (MAP), was collected from worldclim (average for the years 1960-1990; Hijmans et al. 2005). For palaeoclimate, we used glacial-interglacial MAT velocity and glacial-interglacial MAP velocity, which were the ratio between the rate of climate change across time and space (Loarie et al. 2009; Feng et al. 2016). Campus age and area, as well as the population density around the campus were used as anthropogenic factors. Population density data in the year 2017 was extracted by campus coordinates from the History Database of the Global Environment (http:// www.pbl.nl/hyde, Goldewijk et al. 2011).

\section{Statistical analyses}

Bird species richness of each campus was the number of all resident birds recorded in the four visits. Phylogenetic and functional structure were represented by Net Relatedness Index (NRI) (Webb et al. 2002). NRI is computed as:

$$
\mathrm{NRI}=-1 \times \frac{\mathrm{MPD}_{\mathrm{obs}}-\text { meanMPD }}{\text { rnd }}
$$

$M P D_{\text {obs }}$ is the observed mean pairwise phylogenetic distance (MPD) of birds in a campus; meanMPD ${ }_{\text {rnd }}$ is the mean MPD of the null models (null model = "taxa labels" and were run 999 times), and $\operatorname{sdMPD}_{\text {rnd }}$ is the standard deviation of MPD of the null models. Positive NRI means birds in a campus are more closely related/similar than expected (clustered), while negative NRI means birds in a campus are more distantly related/dissimilar than expected (over-dispersed) (Webb et al. 2002).

To compare the regression coefficients, all dependent and independent variables were standardized (standard deviation $=1$ and mean $=0$ ) before analyses. Single-variable ordinary least squares (OLS) models were used to estimate the relationships between bird species richness, phylogenetic structure, functional structure and each associated variable. To account for spatial autocorrelation in regression residuals, simultaneous autoregressive (SAR) models were also used for single-variable analyses. In addition, climate variables and human factors could indirectly affect bird diversity through their effects on plant species richness. To assess the direct and indirect effects of these variables on bird diversity, structural equation models (SEM) were also implemented.

In addition, glacial-interglacial MAP velocity was highly correlated with MAT ( 0.72$)$, glacial-interglacial MAT velocity (0.65) and Area (0.69), thus glacialinterglacial MAP velocity was excluded for SEM models (Additional file 1: Table S2). Also, since some variales were weakly associated with bird diversity indices, only the five variables with the highest associations with bird diversity were included in the SEM models. Lastly, because of the high correlations between MAT and campus area $(-0.60)$, we divided them into two groups for SEM models (Additional file 1: Table S2, Fig. 2; Additional file 2: Figure S3). All analyses were conducted in R (R Core Team 2016), and packages of vegan (Oksanen et al. 2015), spdep (Bivand et al. 2015) and lavaan (Rosseel 2012) were used.

\section{Results}

Twenty-nine resident bird species were recorded in the 20 university campuses, accounting for $26 \%$ of the resident birds in Inner Mongolia. Resident bird species richness in these campuses ranged from 4 (Manzhouli College of Inner Mongolia University) to 11 (Inner Mongolia University and Inner Mongolia University of Finance and Economics). Notably, there were one near threatened (Sitta villosa), one data deficient species (Rhodopechys obsoletus) in IUCN red list catalogue, and one Chinese endemic species (Garrulax davidi).

Single-variable ordinary least square and simultaneous autoregressive models showed similar association patterns (Table 1). Specifically, bird species richness significantly increased with higher precipitation, while phylogenetic and functional structure significantly decreased with precipitation (Fig. 1; Table 1), indicating there were less birds with more clustered structure of 
Table 1 Relationships between resident bird species richness, phylogenetic structure (Phylo NRI), functional structure (Funct NRI) and each associated variable by ordinary least squares (OLS) and simultaneous autoregressive (SAR) models

\begin{tabular}{|c|c|c|c|c|c|c|c|c|c|c|c|c|}
\hline & \multicolumn{4}{|c|}{ Species richness } & \multicolumn{4}{|c|}{ Phylo NRI } & \multicolumn{4}{|c|}{ Funct NRI } \\
\hline & Coef_ols & $r_{- \text {ols }}^{2}$ & Coef $_{- \text {sar }}$ & $r_{-s a r}^{2}$ & Coef_ols & $r_{- \text {ols }}^{2}$ & Coef $_{-s a r}$ & $r_{-s a r}^{2}$ & Coef_ols & $r_{-o l s}^{2}$ & Coef_sar $_{-}$ & $r_{-s a r}^{2}$ \\
\hline MAT & 0.52 & $0.27^{*}$ & 0.52 & $0.31^{* *}$ & -0.22 & 0.05 & -0.17 & 0.13 & -0.18 & 0.03 & -0.15 & 0.04 \\
\hline MAP & 0.45 & $0.20^{*}$ & 0.44 & $0.22^{*}$ & -0.23 & 0.05 & -0.66 & $0.38^{* *}$ & -0.54 & $0.29^{*}$ & -0.55 & $0.41^{* *}$ \\
\hline Velo $_{\text {MAT }}$ & 0.05 & 0 & 0.06 & 0.04 & 0.28 & 0.08 & 0.14 & 0.12 & 0 & 0 & -0.04 & 0.02 \\
\hline Velo $_{\text {MAP }}$ & -0.31 & 0.10 & -0.31 & 0.13 & 0.30 & 0.09 & 0.24 & 0.15 & 0.22 & 0.05 & 0.20 & 0.06 \\
\hline Plant $_{S R}$ & 0.52 & $0.27^{*}$ & 0.49 & $0.27^{* *}$ & 0.16 & 0.03 & 0.06 & 0.10 & -0.10 & 0.01 & -0.20 & 0.05 \\
\hline Area & 0.02 & 0 & 0.04 & 0.04 & 0.18 & 0.03 & 0.14 & 0.12 & 0.29 & 0.08 & 0.30 & 0.11 \\
\hline Age & -0.16 & 0.02 & -0.14 & 0.06 & -0.25 & 0.06 & -0.19 & 0.14 & -0.19 & 0.04 & -0.22 & 0.06 \\
\hline Population & 0.09 & 0.01 & -0.04 & 0.04 & -0.06 & 0 & -0.01 & 0.10 & -0.13 & 0.02 & -0.26 & 0.08 \\
\hline
\end{tabular}

MAT and MAP are mean annual temperature and precipitation. Velo ${ }_{\text {MAT }}$ and Velo MAP $_{\text {are glacial-interglacial velocity in MAT and MAP. Plant }}$ is plant species richness. Area, Age and Population are campus area, age and population density. Coefficients (Coef) and $r^{2}$ were given. And $r^{2}$ of significant variables were in italics. ${ }^{*} p<0.05$; ${ }^{* *} p<0.01$

bird communities in dry regions. In addition, bird species richness also significantly increased with higher temperature and plant species richness (Fig. 1; Table 1).

Moreover, structural equation models also showed that bird species richness was positively correlated with temperature and precipitation (Fig. 2a). Temperature could directly and indirectly affect phylogenetic structure of bird communities (Fig. 2b). Precipitation was also negatively associated with functional structure, again indicating a more clustered functional structure of bird communities in dry regions (Fig. 2c).

\section{Discussion}

Being the first study for urban bird diversity across Inner Mongolia, we found 29 resident bird species in 20 university campuses. Notably, mean annual precipitation consistently played an important role in determining bird species richness (positive), phylogenetic (negative) and functional structure (negative), suggesting the dominant effect of water on bird diversity patterns in this arid and semiarid region, even in the urban ecosystem. Meanwhile, the positive relation between woody plant species richness and bird species richness provides important implication guidance for biodiversity conservation in urban ecosystem.

\section{Effect of contemporary climate}

Many studies have shown that contemporary climate is one of the important factors affecting bird species richness (Currie 1991; van Rensburg et al. 2002; H-Acevedo and Currie 2003; Hawkins et al. 2005; Li et al. 2013). The productivity hypothesis predicts that the increase in ambient energy could provide food resources for more animals by increasing net primary productivity, thus indirectly affect biodiversity (Brown 1981). A recent study of bird diversity in Chinese university campuses finds a significant increase of bird species richness with precipitation (Zhang et al. 2018). Another study in South Africa also suggests that bird species richness has a significantly positive relationship with precipitation (van Rensburg et al. 2002). Consistent with these studies, our analyses also found a significant and positive correlation between bird species and precipitation (range from 142 to $396 \mathrm{~mm}$ ). In arid and semiarid regions, the limiting effect of rainfall on primary productivity may lead to this strong correlation (van Rensburg et al. 2002). Higher precipitation could promote higher primary productivity, thereby supporting more bird species.

Furthermore, we also found significant and negative correlations between precipitation and both phylogenetic and functional structure. In other words, relative dry university campuses tended to have lower bird species richness and relatively clustered/similar phylogenetic and functional structure. This result further confirms the finding of a previous study in natural environments of Inner Mongolia, i.e., regions with lower bird species richness have more clustered phylogenetic structure (Liang et al. 2018). This may suggest that environmental filtering leads to the accumulation of closely related species in dry regions. The phylogenetic niche conservatism hypothesis predicts that species in a colder or drier region tend to be closely related to each other (Qian et al. 2013). According to the phylogenetic conservatism of traits, closely related species tend to be similar in ecological characters, thus harsh environments may also harbor groups of species with similar functional traits. Another study also concludes that severe drought sustains a subset of species with particular functional traits (Olden et al. 2004).

In addition, the ambient energy hypothesis predicts that energy may directly affect the geographical pattern 

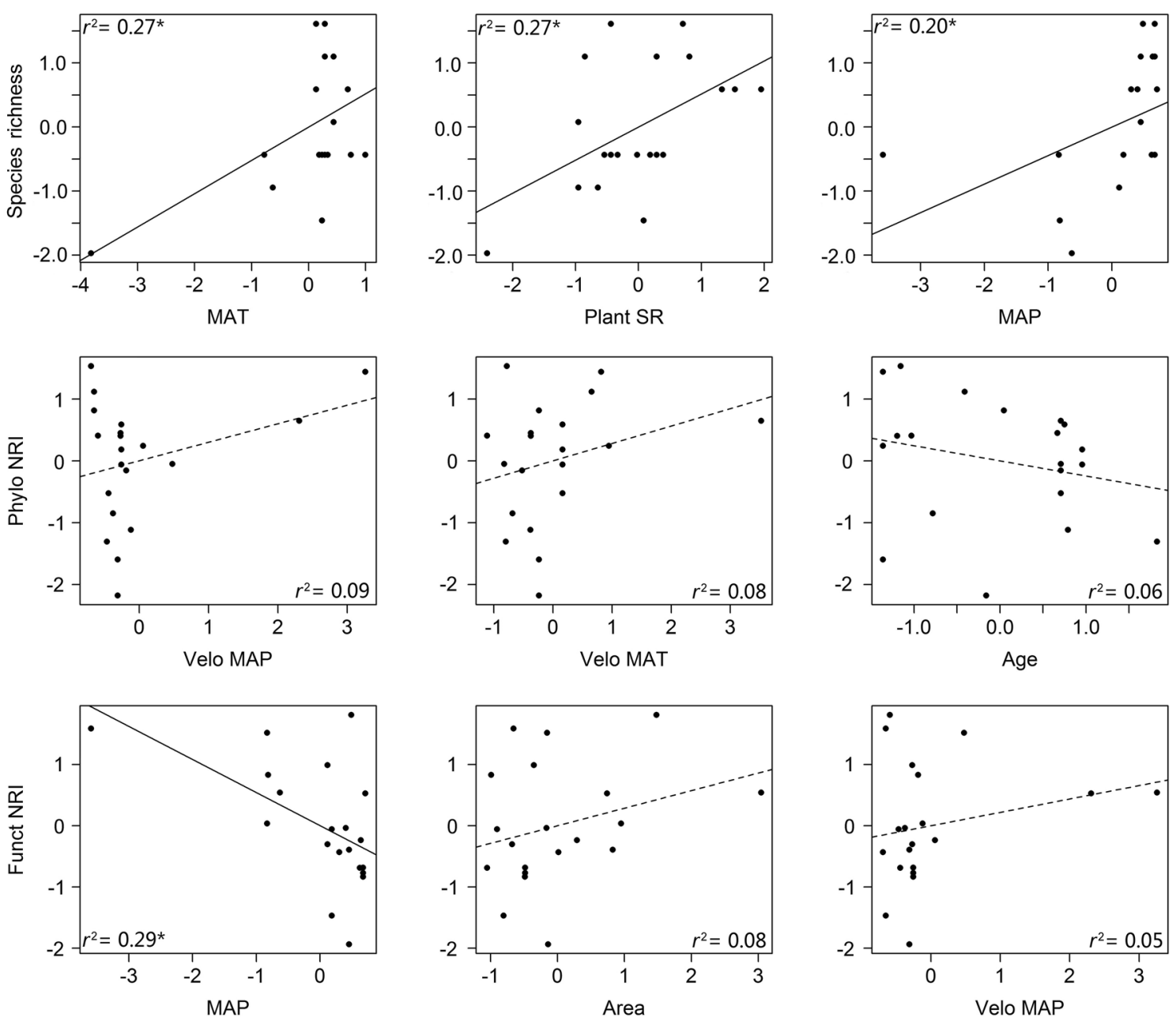

Fig. 1 Scatter plots of bird species richness, phylogenetic structure (Phylo NRI) and functional structure (Funct NRI) against their three most associated variables assessed by ordinary least squares (OLS) models, which were mean annual temperature (MAT), plant species richness (Plant SR) and mean annual precipitation (MAP) for species richness, glacial-interglacial velocity in MAP (Velo MAP), glacial-interglacial velocity in MAT (Velo MAT), and campus age (Age) for Phylo NRI, MAP, campus area (Area) and Velo MAP for Funct NRI, respectively. Linear regression fits and $r^{2}$ were given. Dashed lines represented that the correlations were not significant. ${ }^{*} p<0.05$

\section{a}

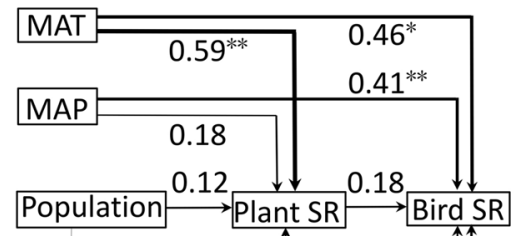

Age

$-0.06$

0.10 b

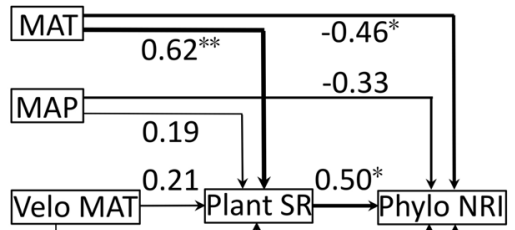

Age
C

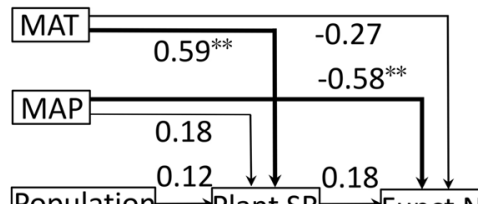

Fig. 2 Results of structural equation models examining the direct and indirect effects of mean annual temperature (MAT), mean annual precipitation (MAP), glacial-interglacial velocity in MAT (Velo MAT), campus population density (Population) and age (Age), and plant species richness (Plant SR) on bird species richness (Bird SR, a), phylogenetic structure (Phylo NRI, b), and functional structure (Funct NRI, c). Standardized regression coefficients were given, and the strength of the effects was proportional to line width. ${ }^{*} p<0.05,{ }^{* *} p<0.01$ 
of species richness in a region through the physiological limitations of animals (Currie 1991; Turner 2004). A study in British shows that summer and winter migratory birds are related to summer temperatures and winter temperatures respectively, while resident birds are related to both summer temperatures and winter temperatures (Turner et al. 1988). Consistently, our results also showed that bird species richness was significantly and positively correlated with the mean annual temperature, that is, bird species richness was lower in colder campuses. It is possible that regions with low temperatures are limiting more bird species to live in. It is also possible that low temperature could lead to limited food resources, such as plants and insects, resulting in low bird species richness. A study for terrestrial birds concludes that temperature and precipitation might influence bird diversity pattern via productivity (Hawkins et al. 2003).

\section{Effect of woody plant species richness}

On a broad scale, species richness of plants and animals has strong covariance with climate change and both increase with productivity (Waide et al. 1999). Meanwhile, plant species richness may directly and indirectly affect birds species richness (H-Acevedo and Currie 2003; Hawkins et al. 2003). Our results showed a significant and positive correlation between species richness of woody plants and birds in university campuses, that is, campuses with more woody plants supporting more bird species. A study in Mexican also concludes that insectivorous birds are more abundant in larger green space with taller trees, more tree and shrub species, and more vegetation cover in adjacent landscape in winter (Carbo-Ramirez and Zuria 2011). It has been suggested that retaining remnant trees can help to increase bird species richness and abundance, and even scattered vegetation also has important impacts on bird diversity in urban landscapes (Barth et al. 2015). Complexity of vegetation structure and woody plant species richness could provide shelter and food for diverse birds, therefore promote higher bird species richness, and are key factors of urban planning for bird species conservation (Evans et al. 2009; Aronson et al. 2014; Huang et al. 2015).

Moreover, although both ordinary least square and simultaneous autoregressive showed weak association between plant species richness and bird phylogenetic structure, structural equation models showed a significant and positive correlation between these two variables, which may be biased by the strong correlation between temperature and plant species richness. Although a study in Beijing shows that the coverage of deciduous trees could increase the evolutionary distinctiveness of bird communities in urban parks (Morelli et al. 2017). In this study, higher values of phylogenetic
NRI in Chifeng College and Manzhouli College were found, which supported the largest and smallest plant species richness respectively, indicating that plant species richness maybe not the key factor that affecting bird phylogenetic structure.

\section{Effect of human factors}

Previous studies have indicated that size, age and population density of green spaces could affect urban bird diversity (Fernández-Juricic 2000; Carbo-Ramirez and Zuria 2011; Gagné et al. 2016). Generally, larger area could provide more food and habitat resources, and vegetation cover and complexity would increase over time, both of which would benefit bird diversity (Fernández-Juricic 2000). In contrast, human induced disturbance, habitat loss and fragmentation have negative effects (Gagné et al. 2016). However, recent studies for birds in Chinese urban parks and university campuses have reported that climate is more important than anthropogenic impacts on bird diversity at broad scales (Zhang et al. 2018; Liu et al. 2019). Consistently, we also found that the three anthropogenic factors had no significant effects on bird diversity. Probably because that the kinds of birds that inhabit urban greenspace generally are either human commensals (e.g., pigeons, starlings, sparrows, swallows) or the kinds of birds that rapidly get used human activity in return for food (e.g., many frugivores). Therefore, our results again indicate the important role of precipitation in shaping bird diversity in this arid and semiarid region.

\section{Conclusions}

Being the first study on bird diversity in university campuses in arid and semiarid Inner Mongolia, we find that precipitation is the dominant driver for taxonomic diversity, phylogenetic and functional structure of bird communities, even in the urban ecosystem. In addition, woody plant species richness is also important for bird species richness, suggesting that vegetation structure should be considered to protect bird diversity in city planning.

\section{Supplementary information}

Supplementary information accompanies this paper at https://doi. org/10.1186/s40657-020-00212-x.

Additional file 1: Table S1. List of abundance of all 68 species in 20 university campuses. Table S2. Correlations among explanatory variables.

Additional file 2: Figure S1. Location of university campuses. Figure S2. Species accumulation curve of University campus bird. Figure S3. Results of structural equation models examining the direct and indirect effects of campus area (Area), age (Age), population density (Population), mean annual precipitation (MAP) and plant species richness (Plant SR) on bird functional NRI. 


\section{Acknowledgements \\ Not applicable.}

\section{Authors' contributions}

GF designed the study; CL, JL, NW and BP collected the data; GF and CL analyzed the data and wrote the paper. All authors read and approved the final manuscript.

\section{Funding}

GF was supported by the National Natural Science Foundation of China (41861004) and the Inner Mongolia Grassland Talent (12000-12102228).

\section{Availability of data and materials}

The raw data that we collected are available upon request.

\section{Ethics approval and consent to participate}

Not applicable.

\section{Consent for publication}

Not applicable.

\section{Competing interests}

The authors declare that they have no competing interests.

\section{Author details}

${ }^{1}$ Ministry of Education Key Laboratory of Ecology and Resource Use of the Mongolian Plateau \& Inner Mongolia Key Laboratory of Grassland Ecology, School of Ecology and Environment, Inner Mongolia University, Hohhot 010021, China. ${ }^{2}$ College of Life Sciences, Inner Mongolia University, Hohhot 010070 , China. ${ }^{3}$ Inner Mongolia University of Finance and Economics, Hohhot 010051, China.

\section{Received: 25 March 2020 Accepted: 15 July 2020}

Published online: 22 July 2020

\section{References}

Aronson MFJ, La Sorte FA, Nilon CH, Katti M, Goddard MA, Lepczyk CA, et al. A global analysis of the impacts of urbanization on bird and plant diversity reveals key anthropogenic drivers. Proc Biol Sci. 2014;281:20133330.

Barth BJ, FitzGibbon SI, Wilson RS. New urban developments that retain more remnant trees have greater bird diversity. Landsc Urban Plan. 2015:136:122-9.

Bivand R, Altman M, Anselin L, Assunção R, Berke O, Bernat A, et al. spdep: spatial dependence: weighting schemes, statistics and models. $R$ package version 0.5-92. 2015. http://CRAN.R-project.org/package=spdep.

Brown JH. Two decades of homage to santa rosalia: toward a general theory of diversity. Integr Comp Biol. 1981;21:877-88.

Carbo-Ramirez P, Zuria I. The value of small urban greenspaces for birds in a Mexican city. Landsc Urban Plan. 2011;100:213-22.

Concepción ED, Obrist MK, Moretti M, Altermatt F, Baur B, Nobis MP. Impacts of urban sprawl on species richness of plants, butterflies, gastropods and birds: not only built-up area matters. Urban Ecosyst. 2016;19:225-42.

Conole LE, Kirkpatrick JB. Functional and spatial differentiation of urban bird assemblages at the landscape scale. Landsc Urban Plan. 2011;100:11-23.

Cornelis J, Hermy M. Biodiversity relationships in urban and suburban parks in Flanders. Landsc Urban Plan. 2004;69:385-401.

Currie DJ. Energy and large-scale patterns of animal- and plant-species richness. Am Nat. 1991;137:27-49.

de Toledo MCB, Donatelli RJ, Batista GT. Relation between green spaces and bird community structure in an urban area in Southeast Brazil. Urban Ecosyst. 2012;15:111-31.

Drummond AJ, Rambaut A. BEAST: Bayesian evolutionary analysis by sampling trees. BMC Evol Biol. 2007;7:214

Evans KL, Newson SE, Gaston KJ. Habitat influences on urban avian assemblages. Ibis. 2009;151:19-39.

Feng G, Mao L, Sandel B, Swenson NG, Svenning J. High plant endemism in China is partially linked to reduced glacial-interglacial climate change. J Biogeogr. 2016:43:145-54.
Ferenc M, Sedlacek O, Fuchs $R$, Dinetti M, Fraissinet M, Storch D. Are cities different? Patterns of species richness and beta diversity of urban bird communities and regional species assemblages in Europe. Glob Ecol Biogeogr. 2014;23:479-89.

Fernández-Juricic E. Bird community composition patterns in urban parks of Madrid: the role of age, size and isolation. Ecol Res. 2000;15:373-83.

Gagné SA, Sherman PJ, Singh KK, Meentemeyer RK. The effect of human population size on the breeding bird diversity of urban regions. Biodivers Conserv. 2016:25:653-71.

Goldewijk KK, Beusen A, van Drecht G, de Vos M. The HYDE 3.1 spatially explicit database of human-induced global land-use change over the past 12,000 years. Glob Ecol Biogeogr. 2011;20:73-86.

$\mathrm{H}$-Acevedo D, Currie DJ. Does climate determine broad-scale patterns of species richness? A test of the causal link by natural experiment. Glob Ecol Biogeogr. 2003;12:461-73.

Hawkins BA, Porter EE, Diniz-Filho JAF. Productivity and history as predictors of the latitudinal diversity gradient of terrestrial birds. Ecology. 2003:84:1608-23.

Hawkins BA, Diniz-Filho JAF, Soeller SA. Water links the historical and contemporary components of the Australian bird diversity gradient. J Biogeogr. 2005;32:1035-42.

Hijmans RJ, Cameron SE, Parra JL, Jones PG, Jarvis A. Very high resolution interpolated climate surfaces for global land areas. Int J Climatol. 2005:25:1965-78.

Huang Y, Zhao YZ, Li SH, von Gadow K. The effects of habitat area, vegetation structure and insect richness on breeding bird populations in Beijing urban parks. Urban For Urban Green. 2015;14:1027-39.

Jetz W, Thomas GH, Joy JB, Hartmann K, Mooers AO. The global diversity of birds in space and time. Nature. 2012;491:444-8.

Jiang Z, Jiang J, Wang Y, Zhang Y, Li L, Xie F, et al. Red list of China's vertebrates. Biodivers Sci. 2016:24:500-51 (in Chinese).

Lepczyk CA, Flather CH, Radeloff VC, Pidgeon AM, Hammer RB, Liu J. Human impacts on regional avian diversity and abundance. Conserv Biol. 2008;22:405-16.

Leveau LM. Bird traits in urban-rural gradients: how many functional groups are there? J Ornithol. 2013:154:655-62.

Li L, Wang Z, Zerbe S, Abdusalih N, Tang Z, Ma M, et al. Species richness patterns and water-energy dynamics in the Drylands of Northwest China. PLOS ONE. 2013;8:e66450.

Liang C, Feng G, Si X, Mao L, Yang G, Svenning JC, et al. Bird species richness is associated with phylogenetic relatedness, plant species richness, and altitudinal range in Inner Mongolia. Ecol Evol. 2018:8:53-8.

Liu J, Bai H, Ma H, Feng G. Bird diversity in Chinese urban parks was more associated with natural factors than anthropogenic factors. Urban For Urban Green. 2019;43:126358.

Loarie SR, Duffy PB, Hamilton H, Asner GP, Field CB, Ackerly DD. The velocity of climate change. Nature. 2009;462:1052-5.

Loss SR, Ruiz MO, Brawn JD. Relationships between avian diversity, neighborhood age, income, and environmental characteristics of an urban landscape. Biol Conserv. 2009;142:2578-85

McDonald RI. Global urbanization: can ecologists identify a sustainable way forward? Front Ecol Environ. 2008;6:99-104

McKinney ML. Effects of urbanization on species richness: a review of plants and animals. Urban Ecosyst. 2008;11:161-76.

Morelli F, Benedetti Y, Su T, Zhou B, Moravec D, Šímová P, et al. Taxonomic diversity, functional diversity and evolutionary uniqueness in bird communities of Beijing's urban parks: effects of land use and vegetation structure Urban For Urban Green. 2017:23:84-92.

Oksanen J, Blanchet FG, Kindt R, Legendre P, Minchin PR, O'Hara RB, et al. vegan: Community ecology package. 2015. http://cran.r-project.org/ package $=$ vegan

Olden JD, Poff NL, Douglas MR, Douglas ME, Fausch KD. Ecological and evolutionary consequences of biotic homogenization. Trends Ecol Evol. 2004:19:18-24.

Palacio FX, Ibañez LM, Maragliano RE, Montalti D. Urbanization as a driver of taxonomic, functional and phylogenetic diversity loss in bird communities. Can J Zool. 2018;96:cjz-2018-0008.

Petchey OL, Gaston KJ. Functional diversity: back to basics and looking forward. Ecol Lett. 2010;9:741-58. 
Qian H, Zhang Y, Zhang J, Wang X. Latitudinal gradients in phylogenetic relatedness of angiosperm trees in North America. Glob Ecol Biogeogr. 2013;22:1183-91.

R Core Team. R: a language and environment for statistical computing. Vienna: R Foundation for Statistical Computing; 2016.

Rosseel Y. lavaan: an R package for structural equation modeling. J Stat Softw 2012;48:1-36.

Sol D, Gonzalez-Lagos C, Moreira D, Maspons J, Lapiedra O. Urbanisation tolerance and the loss of avian diversity. Ecol Lett. 2014;17:942-50.

Thompson PS, Greenwood JJD, Greenaway K. Birds in European gardens in the winter and spring of 1988-89. Bird Study. 1993;40:120-34.

Turner JRG. Explaining the global biodiversity gradient: energy, area, history and natural selection. Basic Appl Ecol. 2004;5:435-48.

Turner JRG, Lennon JJ, Lawrenson JA. British bird species distributions and the energy theory. Nature. 1988;335:539-41.

van Rensburg BJ, Chown SL, Gaston KJ. Species richness, environmental correlates, and spatial scale: a test using South African birds. Am Nat. 2002;159:566-77.
Waide R, Willig M, Steiner C, Mittelbach G, Gough L, Dodson S, et al. The relationship between productivity and species richness. Annu Rev Ecol Syst. 1999;30:257-300.

Wang Y, Si X, Bennett PM, Chen C, Zeng D, Zhao Y, et al. Ecological correlates of extinction risk in Chinese birds. Ecography. 2018;41:782-94.

Webb CO, Ackerly DD, McPeek MA, Donoghue MJ. Phylogenies and community ecology. Annu Rev Ecol Syst. 2002;33:475-505.

Wu J, Zhang Q, Li A, Liang C. Historical landscape dynamics of Inner Mongolia: patterns, drivers, and impacts. Landsc Ecol. 2015;30:1579-98.

Xu R. Fauna of Inner Mongolia, vol. III. Hohhot: Inner Mongolia University Press; 2007 (in Chinese)

Xu R. Fauna of Inner Mongolia, vol. IV. Hohhot: Inner Mongolia University Press; 2015 (in Chinese).

Zhang W, Liang C, Liu J, Si X, Feng G. Species richness, phylogenetic and functional structure of bird communities in Chinese university campuses are associated with divergent variables. Urban Ecosyst. 2018;21:1213-25.
Ready to submit your research? Choose BMC and benefit from:

- fast, convenient online submission

- thorough peer review by experienced researchers in your field

- rapid publication on acceptance

- support for research data, including large and complex data types

- gold Open Access which fosters wider collaboration and increased citations

- maximum visibility for your research: over 100M website views per year

At BMC, research is always in progress.

Learn more biomedcentral.com/submissions 